\title{
Erratum to: \\ The Myths of Health Care
}

\author{
Paola Adinolfi and Elio Borgonovi
}

\section{Erratum to:}

\section{P. Adinolfi and E. Borgonovi (eds.), The Myths of Health} Care, https://doi.org/10.1007/978-3-319-53600-2

In the original version of the book, the belated correction to update the affiliations of authors have to be incorporated in BookFrontmatter, Chaps. 4, 10 and 11. The erratum book has been updated with the changes.

\footnotetext{
The updated online version of these chapters can be found at https://doi.org/10.1007/978-3-319-53600-2_4 https://doi.org/10.1007/978-3-319-53600-2_10 https://doi.org/10.1007/978-3-319-53600-2_11 https://doi.org/10.1007/978-3-319-53600-2 